\title{
Retraction Note: The Evaluation of Reactor Performance by Using Flibe and Flinabe Molten Salts in the APEX Hybrid Reactor
}

\author{
Turgay Korkut • Aybaba Hançerlioğulları
}

Published online: 22 April 2012

(C) Springer Science+Business Media, LLC 2012

\section{Retraction to: J Fusion Energ (2012) 31:151-159 DOI 10.1007/s10894-011-9441-0}

This paper has been retracted. The authors of this article have realized some serious mistakes in Monte Carlo simulations. Therefore, APEX reactor described in this paper is a wrong model. So, Table 3, Figs. 8-12 and performance evaluation of reactor (in Conclusions) were produced by incorrect simulation results. Therefore, the authors would like to retract their article "The Evaluation of Reactor Performance by using Flibe and Flinabe Molten Salts in the APEX Hybrid Reactor." The authors apologize to the readers, reviewers and editors of the Journal of Fusion Energy for publication of incorrect data.

The online version of the original article can be found under doi:10.1007/s10894-011-9441-0.

T. Korkut $(\varangle)$

Department of Physics, Faculty of Science and Art, Ibrahim

Cecen University, 04100 Agri, Turkey

e-mail: turgaykorkut@hotmail.com

A. Hançerlioğulları

Department of Physics, Faculty of Science and Art, Kastamonu

University, 37100 Kastamonu, Turkey 